\title{
A Study of Tourist Police Translation Problems, Translation Needs and Cognitive Fitness
}

\author{
Hussam A. Qaddomi \\ Head of Modern Languages Department, Al Istiqlal University, Jericho, Palestine
}

\begin{abstract}
This study aimed at identifying the Palestinian tourist police translation problems, translation needs and tourist police cognitive fitness in their workplace. The sample of the study consisted of 69 tourist police officers who serve in different workplaces in Palestine. The researcher administered a five point Likert scale questionnaire to the tourist police serving in different tourists sites in Palestine. Findings revealed that translation problems due to the linguistic competence were ranked as high. In addition, non-linguistic translation problems that were ranked by tourist police serving in their workplace were moderate. Moreover, their cognitive fitness skills that might enable them to deal with daily events were moderate. The study also showed that translation needs from the source language into English and vice versa were important as perceived by tourist police officers.
\end{abstract}

Keywords: tourist police, cognitive fitness, problems, needs analysis.

\section{INTRODUCTION}

Palestine envelops a history more than one million years, a meeting place for diverse cultures and ideas religious sites of the three monotheistic faiths played a crucial role in human civilization. Such values encouraged tourists all over the world, despite their religions, to collide in. Accordingly, tourism sector is growing and is playing an integral role in the state's extensive economic growth. More specifically, Palestine became a tourist destination and more popular worldwide. Around 277887 visits were made to tourist sites in the West Bank and 21,922 tourists were from the USA, Canada, and 29,203 from Europe (Palestinian Bureau of Statistics, 2014). A special division working in the Palestinian Police should be there in these sites translating and helping in a lingua franca understood by all, it is English. If a successful communicative translation happens between tourist police and tourists, more satisfaction will happen and consequently more tourists arrival. (Qaddomi, 2014). There is a positive relationship between basic translation (using the two languages professionally), cognitive fitness and being a fully proficient bilingual who maintains regular use of both languages. The current position of English language made it essential for Palestinian personnel in the workplace dealing with tourists to be competent translators in their workplace.

\section{REVIEW OF LITERATURE}

One of the world's largest industries is tourism; the number of people who have traveled internationally has increased from 65 to 560 million over the past 50 years (Dastjerdi and Abdolmaleki, 2012). During the second half of the last century, it is noticed that there has been a rapid expansion of the international multicultural travel industry. This has led to a crucial of those who are working in the tourism sector especially tourist police. Such tendency has necessitated a need to cultural and communication competent translators. Consequently, here comes the importance of introducing a country's tourism attractions in the language of tourists.

As Qaddomi, 2014 cites, determining personnel needs of English in general and translation needs in specific has been one of the fundamental factors and an integral aspect of English for specific purpose (ESP) (Albakrawi, 2013; Prachanan, 2013; Lin, Wu, \& Huang, 2013; Qaddomi, 2013b; Soruc, 2012). It is very important for Palestinian stakeholders to recognize the necessity of equipping such sector with professional police officers who can carrying out effective conversations with tourists, translating and giving information, providing professional services, offering help, answering questions and solving problems (Qaddomi, 2014). Based on the professional translation literature 
there is a distinction between translation and interpretation, where translation refers to the written modality and interpretation. Generally, interpretation refers to the oral modality, whereas the term translation to refer to all modes of reformulating a message from one language (the source language) into another language (the target language) (Bialystok, 1991). Many researchers have highlighted the link between excellence in workplace and excellent language skills (Abdel Ghany and Abdel Latif, 2012; Algren, 2005; Dastjerdi, and Abdolmaleki, 2012; Wang, 2001; Wenyuh, 2012; Quirk, 1985; Tipmontree, 2007). English is considered the most important foreign language in Palestine. When talking about those who work in the tourism sector, mastering translation skills becomes a very essential need especially in situations where police in tourist sites must deal with such as missings, instructions or even dealing with official documents. Qaddomi (2014) stated that tourist police should be trained in Palestine to master English and know its culture. In Palestine, tourism and hospitality university education is very limited to one or two courses in a program at universities or even at the Police Academy. Such courses do not teach in English or tranlation courses to prepare such personnel to workplace; on the contrary, Arabic is the language of instruction at all universities in Palestine (Qaddomi, 2013). Overall, studies concerned translation skills for police and tourism purposes in the Palestinian context are very rare. However, Abdel Ghany and Abdel Latif (2012) stated that the area of teaching English for tourism purposes in other countries in the Arab world has been given much attention, as English became a lingua franca in international tourism industry; still there is a paucity of studies in this area. Moxley-Paquette \& Burkholder (2014) stated that "cognitive fitness is the state of our ability to carry out cognitive tasks with [vigor] and alertness, to learn, and to adapt efficiently to all circumstances"(p.297). Though out the last ten decades, strong supports were given to the importance of cognitive fitness to the development of language i.e., Goldstein (1936).

A number of key cognitive skills are critical for learning and mastering a certain skill especially in security work. For example, Attention Skills that is the ability to attend to incoming information can be observed, and it includes sub-skills such as Sustained Attention. Sustained Attention is the ability to remain focused and on task, and the amount of time we can focus. Police officers should be focused all the time to deal with all events on workplace. Another category is Selective Attention where it is to remain focused and on task while being subjected to related and unrelated sensory input (distractions)). This is a very important skill for tourist police as the tourist police are subject to distractions daily. A third category is Divided Attention, it is one's ability to remember information while performing a mental operation and attending to two things at once (multi-tasking). In such situation, tourist police mental operations and memory should be in best case. It seems that memory is another potential to cognitive skills as it also referred to as the ability to store and recall information. Recalling information that was stored in the past related to spelling, facts, and comprehension is the function of long -term memory. Weak long-term memory skills create symptoms like forgetting names, phone numbers, and doing poorly on tasks. This will automatically affect the work of tourist police and even performance. Another memory skill that tourist police should master is ability to apprehend and hold information in immediate awareness while simultaneously performing a mental operation like interpretation. Police in tourist sector with short-term memory problems may need to look several times at something before copying, have problems following multi-step instructions, or need to have information repeated often. Logic and Reasoning: The ability to reason, form concepts, and solve problems using unfamiliar information or novel procedures. Deductive reasoning extends this problem-solving ability to draw conclusions and come up with solutions by analyzing the relationships between given conditions. Students with underdeveloped logic and reasoning skills will generally struggle with word math problems and other abstract learning challenges. Symptoms of skill weaknesses in this area show up as questions like, "I don't get this", "I need help...this is so hard", or "What should I do first?"Auditory Processing: The ability to analyze, blend, and segment sounds. Auditory processing is a crucial underlying skill for reading and spelling success, and is the number one skill needed for learning to read. Weakness in any of the auditory processing skills will greatly hinder learning to read, reading fluency, and comprehension. Students with auditory processing weakness also typically lose motivation to read. Visual Processing: The ability to perceive, analyze, and think in visual images. This includes visualization, which is the ability to create a picture in your mind of words or concepts. Students who have problems with visual processing may have difficulty following instructions, reading maps, doing word math problems, and comprehending. Processing Speed: The ability to perform simple or complex cognitive tasks quickly. This skill also measures the ability of the brain to work quickly and accurately while ignoring distracting stimuli. Slow processing speed makes every task more difficult. Very often, slow processing is one root of 
ADHD-type behaviors. Symptoms of weaknesses here include homework taking a long time, always being the last one to get his or her shoes on, or being slow at completing even simple tasks.

As the literature review above showed, no study has been conducted to determine tourist police translation problems, needs and cognitive fitness especially in Palestine. Consequently, the rationale of the present study is to determine tourist police translation problems, translation needs and cognitive fitness as building up the tourist police translation capacities in Palestine can contribute to the development of tourism industry.

The present study tried to answer the following questions:

1. What linguistic translation problems do tourist police have while serving in their workplace?

2. What non-linguistic translation problems do tourist police have while serving in their workplace?

3. What cognitive fitness skills do tourist police have?

4. What translation needs do tourist police perceive at the workplace?

Problems with translation- linguistic, non-linguistic and cognitive problems- can result in stress for the tourist police serving day and night in their workplace. There lies the big challenge in the contemporary police administration, which assumes that tourist police service members have appropriate translation skills, cognitive fitness and need not to develop English skills when they are enlisted and start serving at tourism sites. The present study aims to identify the translation problems, needs and cognitive fitness of Palestinian tourist police.

\section{Methodology}

The researcher implemented the descriptive approach as it suits the present study.

\subsection{Population}

The population of this study consisted of all tourist police officers who serve in tourism places in Palestine.

\subsection{Sample}

The study sample consisted of 69 tourist police officers who serve in different workplaces and accompany tourists most of the time.

\subsection{Instrumentation}

Based on the literature review (Qaddomi, 2013), the researcher developed a five -point Likert scale questionnaire to identify Palestinian tourist police needs of translation skills, functional problems facing tourist police in workplace translation and to shed the lights on the cognitive fitness of police officers.

\subsection{Validity of the Questionnaire}

To establish the validity of the instrument, the researcher distributed the questionnaire to a jury who are specialized in linguistics. The content of the questionnaire was reviewed and most of them agreed that the questionnaire suits the purposes of the study. Some suggested adding items related to the linguistic reasons of problems.

\subsection{Reliability of the Questionnaire}

Crombach Alpha Formula was implemented to establish the reliability of the questionnaire where it gained a score of (0.90).

After checking the completion of each questionnaire, the Statistical Package for the Social Sciences (SPSS) was used to analyze the data. The statistical devices employed in this study were as follows:

1. Cronbach Alpha coefficient was used to calculate the reliability of the questionnaire (as stated above).

2. A 5-point Likert scale was used to score the levels translation needs, problems and cognitive skills of tourist police based on the following criteria: 


\section{A- How Important are Translation Skills for Tourist Police}

\begin{tabular}{|l|l|}
\hline Scale & translation skills \\
\hline 1. More than $80 \%$ & very important \\
\hline 2. from $70-79.9 \%$ & important \\
\hline 3. 60-69.9\% & less important \\
\hline 4. 50-59.9.9\% & least important \\
\hline 5. Less than $50 \%$ & not so important \\
\hline
\end{tabular}

\section{B- Translation Problems}

\begin{tabular}{|l|l|}
\hline Scale & Translation Problem \\
\hline 1. More than $80 \%$ & very high \\
\hline 2. from $70-79.9 \%$ & high \\
\hline 3. 60-69.9\% & moderate \\
\hline 4. 50-59.9\% & low \\
\hline 5. Less than 50\% & very low \\
\hline
\end{tabular}

\section{C- Cognitive Fitness}

\begin{tabular}{|l|l|}
\hline Scale & Cognitive fitness level \\
\hline 1. More than $80 \%$ & very high \\
\hline 2. from $70-79.9 \%$ & high \\
\hline 3. 60-69.9\% & moderate \\
\hline 4. 50-59.9\% & low \\
\hline 5. Less than 50\% & very low \\
\hline
\end{tabular}

\section{FINDINGS AND DISCUSSION}

This section deals with the translation problems and needs of translation encountered by tourist police when they interact with tourists in Palestine. Palestinian tourist police were asked to identify their and cognitive fitness. The results were illustrated in tables below.

\section{Results Related to the First Question}

What Linguistic Translation Problems Do Tourist Police Have While Serving in Their Workplace?

To answer this question, means, percentages and SDs were used. Table (1) shows the results.

Table1. Means, percentages and standard deviations of linguistic problems that tourist police suffer from in their workplace (first domain)

\begin{tabular}{|c|c|c|c|c|c|}
\hline No & Linguistic problem & Means & SD & Percentage & $\begin{array}{l}\text { Level of the } \\
\text { problem }\end{array}$ \\
\hline 1 & I find translating information for foreigners difficult. & 3.85 & 1.25 & 77.0 & High \\
\hline 2 & Translating written documents is a problem for me. & 3.66 & 1.21 & 73.2 & High \\
\hline 3 & Translating news is not that easy task. & 3.66 & 0.95 & 73.2 & High \\
\hline 4 & Translating tourists' official documents is very difficult. & 3.76 & 1.20 & 75.2 & High \\
\hline 5 & It is a problem to translate signs and notices. & 3.49 & 0.81 & 69.8 & Moderate \\
\hline 6 & I find it difficult to translate culture- specific items. & 4.14 & 0.89 & 82.8 & Very high \\
\hline 7 & $\begin{array}{l}\text { It is difficult to translate questioning about missings to } \\
\text { obtain data about the description, value, and } \\
\text { circumstances of losing such items }\end{array}$ & 3.47 & 1.30 & 69.4 & moderate \\
\hline 8 & $\begin{array}{l}\text { I translate literally and awkwardly. e.g. Church of Birth } \\
\text { instead of Nativity Church. }\end{array}$ & 3.55 & 0.91 & 71.0 & High \\
\hline 9 & $\begin{array}{l}\text { I do not have sufficient knowledge of spoken/informal } \\
\text { English with its contractions, slang, words and } \\
\text { expressions. }\end{array}$ & 3.93 & 0.86 & 78.6 & High \\
\hline 10 & $\begin{array}{l}\text { I mispronounce some words that make my translation } \\
\text { unintelligible to tourists. }\end{array}$ & 3.47 & 1.26 & 69.4 & Moderate \\
\hline 11 & $\begin{array}{l}\text { I do not have sufficient knowledge of important } \\
\text { languages such as Russian, French, German, and } \\
\text { Italian. }\end{array}$ & 4.16 & 0.83 & 83.2 & Very high \\
\hline 12 & $\begin{array}{l}\text { I cannot understand the message because tourists speak } \\
\text { fast. }\end{array}$ & 3.81 & 0.86 & 76.2 & High \\
\hline
\end{tabular}




\begin{tabular}{|l|l|l|l|l|l|}
\hline \hline $\mathbf{1 3}$ & $\begin{array}{l}\text { I find it difficult to translate immediately because } \\
\text { foreigners are too fast in speech }\end{array}$ & 3.79 & 0.88 & 75.8 & High \\
\hline $\mathbf{1 4}$ & $\begin{array}{l}\text { I face a problem when translating because of the } \\
\text { difference among the many dialects of English. e.g.: the } \\
\text { dropping of the /r/sound }\end{array}$ & 3.66 & 1.04 & 73.2 & High \\
\hline $\mathbf{1 5}$ & $\begin{array}{l}\text { I cannot understand pragmatics or the intended implicit } \\
\text { message of the utterance that tourists produce. }\end{array}$ & 3.38 & 0.91 & 67.6 & Moderate \\
\hline $\mathbf{1 6}$ & $\begin{array}{l}\text { Sometimes it is difficult to translate } \\
\text { ambiguous utterances produced by tourists. }\end{array}$ & 3.76 & 1.22 & 75.2 & High \\
\hline $\mathbf{1 7}$ & $\begin{array}{l}\text { I have a trouble with sound discrimination (phonemic } \\
\text { awareness) that creates difficulty in translation. }\end{array}$ & 3.10 & 1.29 & 62.0 & Moderate \\
\hline $\mathbf{1 8}$ & I pronounce poorly. & 3.40 & 1.41 & 68.0 & Moderate \\
\hline $\mathbf{1 9}$ & Tourists use difficult idioms and collocations. & 3.77 & 1.08 & 75.4 & High \\
\hline & Total score & $\mathbf{3 . 6 8}$ & $\mathbf{0 . 7 4}$ & $\mathbf{7 6 . 2}$ & High \\
\hline
\end{tabular}

As table 1 shows, most tourist police rated all the linguistic problems as high. An important result that is related to items 6 (I find it difficult to translate culture-specific items.) and 11(I do not have sufficient knowledge of important languages such as Russian, French, German, and Italian ) where tourist police rank two of the major problems facing them in their workplace as they gained the highest among the linguistic problems ( $\mathrm{M}=4.14,82.28 \%, \mathrm{M}=4.16,83.2 \%)$. This indicates that the majority of tourist police express a big problem since they rated a very high difficulty in translating culture- specific items and insufficient knowledge of important languages such as Russian, French, German, and Italian as these languages are important in their workplace as they perceive them. Such problems are attributed to the fact that not all tourist police officers are English majors /modern languages majors. They did not take translation courses that enable them to deal with culture specific items in the Target Language. As translation is closely related to culture (Terestyényi, 2011), translatability of culture-specific items has always been in the focus among theorists of translation and translators because these items are problematic ones. On the other hand, tourist police indicated a moderate degree concerning translating signs and notices $(M=3.49,69.8 \%)$, pronunciation $(\mathrm{M}=3.47,69.4 \%)$, and trouble with sound discrimination $(\mathrm{M}=3.10,62.0 \%)$. In addition, other linguistic problems that tourist have are translating information for foreigners, tourist police do not have sufficient knowledge of spoken/informal English with its contractions, slang, words and expressions that tourists use. This may explain the fact that the stakeholders in Palestine should promote tourism industry through preparing tourist police taking language courses including translation skills.

The total score of translation problems that are originally linguistic tourist police suffer from in their workplace was $\mathrm{M}=3.68, \mathrm{SD}=0.74$ and $73.6 \%$. Such percentage is considered as a high one. This indicates that Palestinian tourist police do have translation problems that are originally linguistic (written documents, news, official documents...). Having a moderate level of cognitive fitness $(6.64 \%)$, as the total score in table 3 states, could one source of such problem this is due to the fact that language development is directly related to a person's cognitive fitness (Moxley-Paquette and Burkholder, 2015).

What Non-Linguistic Translation Problems Do Tourist Police have while Serving in their Workplace?

To answer this question, means, percentages and SDs were used. Table (2) shows the results.

Table2. Means, percentages and standard deviations of non-linguistic problems that tourist police suffer from in their workplace (second domain)

\begin{tabular}{|l|l|l|l|l|l|}
\hline No & Non-Linguistic Problems & Means & SD & Percentage & $\begin{array}{l}\text { Level of the } \\
\text { problem }\end{array}$ \\
\hline $\mathbf{1}$ & $\begin{array}{l}\text { Cultural differences may be problematic especially } \\
\text { those related to daily life such as: food, greetings, } \\
\text { customs, time...etc. }\end{array}$ & 3.35 & 1.28 & 67.0 & Moderate \\
\hline $\mathbf{2}$ & $\begin{array}{l}\text { When I translate to foreigners, I find it difficult because } \\
\text { I do not know much information about historical and } \\
\text { geographical places. }\end{array}$ & 4.13 & 0.77 & 82.6 & Very High \\
\hline $\mathbf{3}$ & $\begin{array}{l}\text { When I translate, I cannot give directions in a clear } \\
\text { straightforward and accurate way. }\end{array}$ & 3.91 & 1.00 & 78.2 & High \\
\hline
\end{tabular}




\begin{tabular}{|l|l|l|l|l|l|}
\hline $\mathbf{4}$ & $\begin{array}{l}\text { I do not know how to use non-verbal communication } \\
\text { e.g., body language. }\end{array}$ & 3.15 & 1.55 & 63.0 & Moderate \\
\hline $\mathbf{5}$ & $\begin{array}{l}\text { I sometimes fail to offer help that tourists need in } \\
\text { certain domains such as: health, transportations...etc. }\end{array}$ & 3.06 & 1.35 & 61.2 & Moderate \\
\hline $\mathbf{6}$ & $\begin{array}{l}\text { Sometimes I cannot be attentive, cooperative, and } \\
\text { communicative with tourists. }\end{array}$ & 3.37 & 1.41 & 67.4 & Moderate \\
\hline $\mathbf{7}$ & I am slow in translation. & 3.35 & 1.41 & 67.0 & moderate \\
\hline $\mathbf{8}$ & I am shy when interacting with tourists. & 2.93 & 1.22 & 58.6 & low \\
\hline $\mathbf{9}$ & I try to avoid interacting with tourists. & 2.71 & 1.28 & 54.2 & low \\
\hline & Total score & $\mathbf{3 . 3 3}$ & $\mathbf{0 . 8 6}$ & $\mathbf{6 6 . 6}$ & Moderate \\
\hline
\end{tabular}

It is clear from table 2 above that most tourist police rated all the non-linguistic problems as moderate. What is so exciting is the rank of items 2(When I translate to foreigners, I find it difficult because I do not know much information about historical and geographical places.) and 3 (When I translate, I cannot give directions in a clear straightforward and accurate way) as they gained the highest among the non-linguistic problems where the mean was $(M=4.13,82.06 \%)$ and $(M=3.91$, $78.02 \%)$.

The total score of translation problems that are originally non-linguistic tourist police suffer from in their workplace was $\mathrm{M}=3.33, \mathrm{SD}=0.74$ and $66.6 \%$. Such percentage is considered as a moderate one. This indicates that Palestinian tourist police do have translation problems that are originally nonlinguistic. Such non-linguistic problems are associated with the tourist police lack of knowledge and much information about historical and geographical places where they serve.

\section{What Cognitive Fitness Skills Do Tourist Police Perceive?}

To answer this question, means, percentages and SDs were used. Table (3) shows the results.

Table3. Means, percentages and standard deviations of cognitive fitness skills that tourist police have (third domain)

\begin{tabular}{|l|l|l|l|l|l|}
\hline No & cognitive fitness skills & Means & SD & Percentage & Level \\
\hline $\mathbf{1}$ & $\begin{array}{l}\text { I am able to remain focused on task regardless the amount } \\
\text { of time we can focus. }\end{array}$ & 3.66 & 0.88 & 73.2 & High \\
\hline $\mathbf{2}$ & $\begin{array}{l}\text { I am able to remain focused on task while being subjected } \\
\text { to distractions on the tourism site. }\end{array}$ & 3.11 & 1.05 & 62.2 & Moderate \\
\hline $\mathbf{3}$ & $\begin{array}{l}\text { I am able to remember information while guiding tourists } \\
\text { and translating to them (multi-tasking). }\end{array}$ & 2.94 & 0.97 & 58.8 & low \\
\hline $\mathbf{4}$ & $\begin{array}{l}\text { I am able to recall information that was stored in the past } \\
\text { such as names and phone numbers. }\end{array}$ & 2.89 & 1.15 & 57.8 & low \\
\hline $\mathbf{5}$ & $\begin{array}{l}\text { I am able to reason, form concepts, solve problems, draw } \\
\text { conclusions and come up with solutions. }\end{array}$ & 3.61 & 0.85 & 72.2 & High \\
\hline $\mathbf{6}$ & $\begin{array}{l}\text { I am able to analyze, blend, and segment sounds of the } \\
\text { language that tourists produce. }\end{array}$ & 3.27 & 0.90 & 65.4 & moderate \\
\hline $\mathbf{7}$ & $\begin{array}{l}\text { I am able to perceive, analyze, and think in visual images } \\
\text { such as reading maps for tourists, doing instructions... }\end{array}$ & 3.13 & 1.13 & 62.6 & moderate \\
\hline $\mathbf{8}$ & $\begin{array}{l}\text { I am able to perform simple or complex cognitive tasks } \\
\text { quickly. }\end{array}$ & 3.05 & 0.99 & 61.0 & moderate \\
\hline & Total score & $\mathbf{3 . 2 3}$ & $\mathbf{0 . 5 5}$ & $\mathbf{6 4 . 6}$ & moderate \\
\hline
\end{tabular}

Table three above states that most of tourist police rated their cognitive skills as moderate. Such items represent Auditory Processing, Visual Processing and Speed Processing. Such processes are very crucial underlying skills for language skills. Weakness in any of the auditory processing skills will greatly hinder learning to read, reading fluency, and comprehension. Students with auditory processing weakness also typically lose motivation to read. However, two skills were acute problems to tourist police. For example, performing multi-tasking such as the ability to remember information while guiding tourists and translating to them and the ability to recall information that was stored in the past such as names and phone numbers (Divided Attention). Divided Attention implies the ability to remember information while performing a mental operation and attending to two things at once. Generally, it is very clear from the total score above $(M=3.23,64.6 \%)$ that tourist police cognitive skills still need to be developed. 
What Translation Needs do Tourist Police Perceive at the Workplace from the Source Language (Arabic) into English Language?

To answer this question, means, percentages and SDs were used. Table (4) shows the results.

Table4. Means, percentages and standard deviations of translation needs that tourist police need in their workplace (Translation needs from the Arabic into English language)

\begin{tabular}{|l|l|l|l|l|l|}
\hline No & $\begin{array}{l}\text { Translation needs from the Arabic into } \\
\text { English language }\end{array}$ & Means & SD & Percentage & $\begin{array}{l}\text { Level of } \\
\text { importance }\end{array}$ \\
\hline $\mathbf{1}$ & $\begin{array}{l}\text { I need translation to translate information for } \\
\text { foreigners in tourist places. }\end{array}$ & 3.97 & 0.91 & 79.4 & Important \\
\hline $\mathbf{2}$ & I need translation to translate written documents. & 4.00 & 1.11 & 80.0 & Very important \\
\hline $\mathbf{3}$ & I need translation to translate news. & 3.73 & 1.22 & 74.6 & Important \\
\hline $\mathbf{4}$ & $\begin{array}{l}\text { I need translation to translate tourists' official } \\
\text { documents. }\end{array}$ & 4.00 & 0.96 & 80.0 & Important \\
\hline $\mathbf{5}$ & I need translation to translate signs and notices. & 3.81 & 1.12 & 76.2 & Important \\
\hline & Total score & $\mathbf{3 . 9 0}$ & $\mathbf{0 . 7 8}$ & $\mathbf{7 8}$ & Important \\
\hline
\end{tabular}

Table 4 above shows that the most important skill in translation that tourist police really need and perceived is translation skill to translate written documents $(\mathrm{M}=4.00,80.0 \%)$. What is so interesting is what table 1 above stated that tourist police have acute problem in translating written documents as it was ranked as high problem. Another noticeable result is item $1(\mathrm{M}=3.97,79.4 \%)$ was rated as important skill, simultaneously, tourist police find it difficult to translate information for foreigners in tourist places as stated in table 1 above. Concerning the rest of the skills that tourist police perceived in table 4 above, they were ranked as important $(M=3.73$ to $M=3.81)$. This is very crucial because tourist police feel that mastering basic skills in translation is important to them because they need such skills in the field.

\section{What Translation needs do Tourist Police Perceive at the Workplace from English Language into the Target Language?}

To answer this question, means, percentages and SDs were used. Table (5) shows the results.

Table5. Means, percentages and standard deviations of translation needs that tourist police need in their workplace (Translation needs from English language into the target language)

\begin{tabular}{|l|l|l|l|l|l|}
\hline No & $\begin{array}{l}\text { Translation needs from English language into } \\
\text { Arabic }\end{array}$ & Means & SD & Percentage & $\begin{array}{l}\text { Level of } \\
\text { importance }\end{array}$ \\
\hline $\mathbf{1}$ & $\begin{array}{l}\text { I need translation to translate information for } \\
\text { foreigners in tourist places. }\end{array}$ & 3.80 & 0.96 & 76.0 & Important \\
\hline $\mathbf{2}$ & I need translation to translate written documents. & 3.95 & 0.94 & 79.0 & Very important \\
\hline $\mathbf{3}$ & I need translation to translate news. & 3.53 & 1.15 & 70.6 & Important \\
\hline $\mathbf{4}$ & $\begin{array}{l}\text { I need translation to translate tourists' official } \\
\text { documents. }\end{array}$ & 4.08 & 0.92 & 81.6 & Very Important \\
\hline $\mathbf{5}$ & I need translation to translate signs and notices. & 3.69 & 1.05 & 73.8 & Important \\
\hline & Total score & $\mathbf{3 . 8 1}$ & $\mathbf{0 . 7 3}$ & $\mathbf{7 6 . 2}$ & Important \\
\hline
\end{tabular}

According to table 5, the most important skills in translation from English language into Arabic that tourist police need to master are translating written documents $(\mathrm{M}=4.00,80.0 \%)$ and translating tourists' official documents $(\mathrm{M}=4.08,81.6 \%)$. The table above stated that tourist police feel the need to master translation skills from English language into Arabic as important as translation skills from Arabic into English such as translating news, signs and notices. The total score for this domain is $(\mathrm{M}=$ $3.81,76.2 \%)$. Fulfilling such pressing need plays an integral role in the professional development of tourist police where they can help more, understand tourists better, be self confident and have higher cognitive fitness. Such needs are apparent because tourist police perceive problems in translation as stated in table 3 above.

\section{CONClusions AND Further Research}

Despite the fact that tourist police have, as they perceive, linguistic and non-linguistic translation problems, it cannot be neglected that tourism industry has grown and tourist police played a great role to keep such growth in many aspects. However, some of these aspects should be developed so that such growth accelerates faster. Moreover, the study examined the tourist police perceived linguistic 
and non-linguistic translation problems and needs in some of the tourists sites in Palestine, which might not be enough to make generalizations. It is recommended that police organizations and stakeholders set professional development plans in which tourist police officers find relevant translation courses and skills to help them overcome problems of culture specific terms and expressions. Despite of the limitations the present study faced, it is significant for the field of identifying tourist police officers translation problems and cognitive fitness since it provides basis for the further research.

\section{REFERENCES}

Abdel Ghany S.Y. and Abdel Latif M. M.(2012) English language preparation of tourism and hospitality undergraduates in Egypt: Does it meet their future workplace requirements? Journal of Hospitality, Leisure, Sport \& Tourism Education 11, 93-100.

Algren, B (2005) Ongoing needs Analysis as a factor to Successful Language Learning. Journal of Language and Learning, 1-1, 1-10.

Bialystok, E. (1991) Language processing in bilingual children. Cambridge. CUP.

Dastjerdi, H. and Abdolmaleki, S. (2012) A Study of Translation Problems of Tourism Industry Guidebooks: An Error Analysis Perspective. International Journal of Foreign Language Teaching and Research, 1(1), 71-82.

Goldstein, K. (1936) The problem of the meaning of words based upon observation of aphasic patients. Journal of Psychology, (2) 301-316.

Moxley-Paquette, E.A., \& Burkholder, G. (2015) Testing a structural equation model of languagebased cognitive fitness, Procedia Social and Behavioral Sciences, 112, 64-76. doi: 10.1016 /j.sb spro.2014.01.1140.

Qaddomi, H. A. (2013) English for specific purposes in Palestinian context: Determining EFL cadets' needs at Al Istiqlal University. Theory and Practice in Language Studies, 3(7): 1110-1122.

Qaddomi, H.(2014) English for Palestinian tourist tolice in their workplace: Needs and problems. Journal of Scientific Research in Education, 15.

Quirk R. (1985) The English language in a global context. In Quirk R, Widdowson HG, editors. English in the world: Teaching and learning the language and literature. Cambridge: Cambridge University Press.

Terestyényi, Enikő, (2011) Translating Culture-specific Items in Tourism Brochures. In SKASE Journal of Translation and Interpretation [online]. 2011, vol. 5, no. 2.

Tipmontree, S. (2007) The use and the problems of English and intercultural communication skills of Thai tourist police officers. Master Thesis. University of the Thai Chamber Of Commerce. Retrieved 2015, 20 March fromwww.eprints.utcc.ac.th.

Wang, L. L. (2001) Professional competence required for food and beverage employees working front of the house in international tourist hotels. Doctoral dissertation: National Normal University. Taipei, Taiwan. Retrieved 2015, 20 March fromhttp://core.ac.uk/display/13361644.

Wenyuh, S. (2012) Hotel Employees' Perception on Their Workplace English Use: An Example from Taiwan. US-China Foreign Language, 10(11), 1729-1733.

Citation: Hussam A. Qaddomi. "A Study of Tourist Police Translation Problems, Translation Needs and Cognitive Fitness" International Journal on Studies in English Language and Literature (IJSELL), vol5, no.8, 2017, pp. 22-29. doi:http://dx.doi.org/10.20431/2347-3134.0508004.

Copyright: (C) 2017 Authors. This is an open-access article distributed under the terms of the Creative Commons Attribution License, which permits unrestricted use, distribution, and reproduction in any medium, provided the original author and source are credited. 